\title{
Development and validation of liquid chromatography method for simultaneous determination of multiclass seven antibiotic residues in chicken tissues
}

\author{
Aynalem Lakew ${ }^{1,2}$, Teshome Assefa ${ }^{1}$, Meseret Woldeyohannes ${ }^{1}$, Negussie Megersa ${ }^{2}$ and \\ Bhagwan Singh Chandravanshi $2^{*}$
}

\begin{abstract}
Background: Antibiotics are routinely used on poultry for therapy and prevention of diseases and to enhance animal growth. The objective of this study was to develop and validate a sensitive and reliable liquid chromatography with UV detection (LC-UV) method for the simultaneous determination of seven multiclass antibiotic residues (amoxicillin, ampicillin, penicillin, sulfamethoxazole, gentamicin, ciprofloxacin, and erythromycin) in chicken tissues.
\end{abstract}

Methods: The liquid chromatography method with UV detection was optimized for complete separation of the seven selected antibiotic compounds with reversed phase and isocratic elution using Hypersil BDS-C18 (3 $\mu$ m, $100 \mathrm{~mm} \times 4 \mathrm{~mm}$ ) column. The mobile phase consisted a ratio of $0.05 \mathrm{M} \mathrm{Na}_{2} \mathrm{HPO}_{4}$, acetonitrile and methanol (70:10:20), at UV absorption wavelength of $230 \mathrm{~nm}$. The column thermostat was set at $40^{\circ} \mathrm{C}$, the mobile phase flow

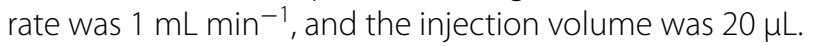

Results: All the seven standard compounds were eluted within $14 \mathrm{~min}$. The results for: linearity, precision, sensitivity, accuracy, specificity, decision limit (CCa), detection capability (CC $\beta$ ), suitability and method robustness were validated according to the criteria of Commission Decision 2002/657/EC guidelines. Calibration plot correlation coefficients ranged from 0.9983 to 0.9998 and the percent relative standard deviations for repeated analysis were below $5 \%$ indicating acceptable method precision. The limits of detection (LODs) and quantification (LOQs) ranged from $0.098-$ $0.255 \mathrm{\mu g} \mathrm{kg}^{-1}$ to $0.297-0.574 \mathrm{\mu g} \mathrm{kg}^{-1}$, respectively. The accuracy study yielded recoveries in the ranges $98.1-107 \%$ for the pure compounds and $94.0-102 \%$ for the spiked drug free chicken tissue samples.

Conclusions: The method was found to be appropriate for simultaneous determination of five different classes of seven antibiotic residues in chicken tissues. Furthermore, this is the first instance for the simultaneous determination of seven multiclass, multi-residues analysis using LC-UV from chicken tissue samples. This is a cost-effective and alternative method with simple instrumentation approach for laboratories that lack highly specialized state-of-the-art instrumentation.

Keywords: Antibiotic residues, Food safety, Food contaminants, Chicken tissue, Liquid chromatography

*Correspondence: bscv2006@yahoo.com

${ }^{2}$ Department of Chemistry, College of Natural and Computational Sciences, Addis Ababa University, P. O. Box 1176, Addis Ababa, Ethiopia Full list of author information is available at the end of the article

\section{Background}

Antibiotics have been routinely used in veterinary medicine and agriculture since the 1950s [1]. The use of antibiotics has not been limited to treating sick animals, but 
also used as feed additives in the animal husbandry to increases animal growth and their productions [2-5].

In poultry production amoxicillin is used to combat respiratory and other bacterial infections [6], ampicillin for promotion of growth, feed efficiency and stimulation of egg production [7], assistance in relieving stress [8], and rehydration of livestock [8]. It is estimated that $80 \%$ of all food-producing animals receive medication for part or most of their lives [6].

Slaughtering the chicken or laying eggs can leave pharmaceutical residues in the tissues and eggs at concentrations that can be harmful to the human health $[9,10]$. Human exposure to the veterinary medicinal products through the uptake of their residues in poultry products has been linked to the development of allergic reactions in the hypersensitive individuals (e.g., penicillin) [6]; carcinogenicity (e.g., sulfamethazine, oxytetracycline, and furazolidone) [11]; hepatotoxicity, reproductive disorders, bone marrow toxicity (e.g., chloramphenicol) [6]; estrogenic, neurotoxicological effects, allergies (e.g., penicillin) [12] as well as induction and generation of resistant strains of human pathogenic bacteria [13].

World Health Organization (WHO) [14], Food and Agriculture Organization (FAO) [15] and Codex Alimentarius Commission (CAC) [16] have set standards for acceptable daily intake (ADI) and maximum residue limits (MRLs) in foods. According to commission regulation (EU), the antibiotic residue MRLs in chicken tissue are: for ciprofloxacin $100 \mu \mathrm{g} \mathrm{kg}^{-1}$, erthyromycin $200 \mu \mathrm{g} \mathrm{kg}$ and $50 \mu \mathrm{g} \mathrm{kg}^{-1}$ for each of amoxicillin, ampicillin, penicillin $\mathrm{G}$ and gentamicin [17]. To ensure the food safety from contamination with antimicrobial residues, its use must be monitored strictly and therefore, sensitive analytical methods are essential to assay these compounds in complex matrices.

Microbiological or screening methods and chromatographic methods have been described for monitoring and detecting antibiotic residues [18]. Recent reviews described the analytical qualitative and quantitative methods that have been developed during the past decade for some antibiotic residues (microbiological approaches, biosensors, and chromatographic methods) [19]. Analytical techniques including liquid chromatography (LC) [20] and gas chromatography (GC) [21] are commonly employed for the separation and determination of compounds in mixtures. The low solubility in organic solvents, insufficiently volatile or too thermally unstable property of some antimicrobials has made it more difficult and time consuming to develop procedures and to determine antibiotic residues using GC [22].

Recent development on the new analytical strategies and confirmatory methods for residue analysis of animal products are based on the liquid chromatography
(LC) and hyphenated techniques such as liquid chromatography-tandem mass spectrometry (LC-MS/MS) [23] and liquid chromatography-quadrupole time of flight mass spectrometry (LC-QToFMS) [24]. Liquid chromatography-triple quadrupole-mass spectrometry (LCQqQ-MS) [25], time-of-flight (ToF) or high-resolution mass spectrometry (HR-MS) resulted in an enormous improvement of analytical parameters such as sensitivity and lower detection limits. Consequently, these enabled the analysts to detect multiclass and multi-component antibiotics in complex biological samples with high sensitivity, specificity and robustness $[26,27]$.

However, the implementation to control the antimicrobial residues is still limited in developing countries like Ethiopia due to lack of the complex laboratory equipment and the high cost required. The way to improve cost-effectiveness is to maximise the number of analytes that may be determined by a single procedure. Multiresidue detection methods using the available single instrument is an alternative for the determination and confirmation of many antibiotic residues simultaneously by LC-UV. Developing such an analytical method is more cost-effective than changing parameters for each analyte for the analysis of real samples.

To the best of our knowledge there is no single LC method reported for the simultaneous determination of the selected seven antibiotic compounds of five different therapeutic classes including three ( $\beta$-lactams), amoxicillin (AMOX), ampicillin (AMPI), penicillin G (PEN G), (sulphonamides), sulfamethoxazole (SULFA) (aminoglycosides), gentamicin (GENTA) (fluoroquinolones), ciprofloxacin (CIP) and (macrolide), erthyromycin (ERYTHRO) in chicken tissue samples. This study attempts to develop a simple, accurate, precise and stable analytical chromatographic method, which can separate and determine the seven selected antibiotic drugs simultaneously in a single optimized method in chicken tissues. The proposed method has been developed and validated as per the Commission Decision 2002/657/ EC guidelines [28]. The developed method is suitable for laboratories that are not equipped with highly specialized state-of-the-art instrumentation.

\section{Materials and methods}

\section{Chemicals and reagents}

Negative concentration chicken tissue control (Charm Scientific) was kind donation from Ethiopian Public Health Institute (EPHI). Antibiotic standard compounds (assigned purity $\geq 99 \%$ ) listed in Table 1 were a kind donation from Ethiopian Food and Drug Administration (EFDA). All the standard solutions were prepared in HPLC grade methanol ( $>99 \%)$ and HPLC grade acetonitrile (>99\%) were from Merck (Germany). Disodium 
Table 1 Physicochemical properties and chemical structures of the selected antibiotics commonly used on poultry production [29, 30]

\begin{tabular}{|c|c|c|c|c|c|}
\hline Class & Compound molecular formula and weight & Chemical structure & $\begin{array}{l}\text { Solubility in } \\
\text { water (mg/ } \\
\mathrm{mL})\end{array}$ & $\log K_{\text {ow }}$ & $\mathrm{p} K_{\mathrm{a}}$ \\
\hline \multirow[t]{3}{*}{$\beta$-Lactams } & Amoxicillin, $\mathrm{C}_{16} \mathrm{H}_{19} \mathrm{~N}_{3} \mathrm{O}_{5} \mathrm{~S}, 365.4 \mathrm{~g} \mathrm{~mol}^{-1}$ & & 3.4 & $0.87,0.97$ & $2.4,2.8,7.2$ \\
\hline & Ampicillin, $\mathrm{C}_{16} \mathrm{H}_{19} \mathrm{~N}_{3} \mathrm{O}_{4} \mathrm{~S}, 349.4 \mathrm{~g} \mathrm{~mol}^{-1}$ & & 10.1 & 1.45 & $2.53,2.77 .3$ \\
\hline & Benzylpenicillin (penicillin $\mathrm{G}$ ), $\mathrm{C}_{16} \mathrm{H}_{18} \mathrm{~N}_{2} \mathrm{O}_{4} \mathrm{~S}, 334.4 \mathrm{~g} \mathrm{~mol}^{-1}$ & & 0.2 & 1.85 & $2.7,2.8$ \\
\hline Fluoro-quinolones & Ciprofloxacin $\mathrm{C}_{17} \mathrm{H}_{18} \mathrm{FN}_{3} \mathrm{O}_{3}, 331.3 \mathrm{~g} \mathrm{~mol}^{-1}$ & & 36 & 0.4 & $3.01,6.38,8.70$ \\
\hline Aminoglycoside & Gentamicin $\mathrm{C}_{21} \mathrm{H}_{43} \mathrm{~N}_{5} \mathrm{O}_{7}, 477.6 \mathrm{~g} \mathrm{~mol}^{-1}$ & & 100 & -1.88 & 8.2 \\
\hline Macrolides & Erythromycin $\mathrm{C}_{37} \mathrm{H}_{67} \mathrm{NO}_{13}, 733.9 \mathrm{~g} \mathrm{~mol}^{-1}$ & & 2 & $3.06,2.48$ & $8.88,8.9$ \\
\hline Sulfonamides & Sulfamethoxazole $\mathrm{C}_{10} \mathrm{H}_{11} \mathrm{~N}_{3} \mathrm{O}_{3} \mathrm{~S}, 253.3 \mathrm{~g} \mathrm{~mol}^{-1}$ & & 0.61 & $0.89,0.48$ & $1.85,5.6$ \\
\hline
\end{tabular}

$\mathrm{K}_{\text {ow: }}$ : the octanol-water partition coefficient

$\mathrm{pK}_{\mathrm{a}}$ : acidity constant

hydrogen phosphates $\left(\mathrm{Na}_{2} \mathrm{HPO}_{4}\right)(>99 \%)$ and orthophosphoric acid $\left(\mathrm{H}_{3} \mathrm{PO}_{4}\right)(>85 \%)$ were from Sigma-Aldrich (USA). Double distilled deionized water used throughout the study was purified using Water Still, 4 LPH, Double distilled, 240 VAC, 50/60 Hzfrom Stuart Aquatron (USA).

\section{Instruments and equipment}

Shimadzu LC-20ad prominence equipped with quaternary pump, and dual wavelength UV detector, column oven and auto sampler (Shimadzu Corporation, Kyoto, Japan) and analytical column Hypersil BDS-C18 (3 $\mu \mathrm{m}, 100 \mathrm{~mm} \times 4 \mathrm{~mm}$ ) (Thermo Fisher Scientific,
Phenomenex, USA) were used for chromatographic separation; data acquisition and processing were accomplished with LC solution software. Syringe membrane filters $0.45 \mu \mathrm{m}$ Millex-HN (Millipore, Bed-ford, MA, USA) for filtration of standards and samples; centrifuge, AX-320 (Tomy Seiko Co., Tokyo, Japan); vortex mixer, Vortex-Genie 2 (Scientific Industries Inc., Bohemia, New York, USA) and ultrasonic machine, B5510J-DTH (Branson, Danbury, CT) were also used. The $\mathrm{pH}$ values of the mobile phases were measured using a Hanna instruments pH meter (Hanna Instruments Inc., Cluj-Napoca Jud, Cluj, Romania); vacuum filtration assembly (Millipore filter cellulose nitrate gridded with $0.22 \mu$ size and 
$47 \mathrm{~mm}$ diameter) attached with vacuum pump and glass support, NS 40/35 joints from Sigma-Aldrich (USA) were used for HPLC solvent purification. Flask (Pyrex), volumetric, class A, w/Pyrex standard taper stopper, $1 \mathrm{~mL}$, Corning 5640-1 (Beijing, China) and R-100 rotary evaporator from Buchi Labortechhnik AG (Switzerland) were used for evaporation of solvents.

\section{Chromatographic conditions}

Chromatographic separation of the selected seven antibiotic standard compounds was achieved with analytical column, Hypersil BDS-C18 $(3 \mu \mathrm{m}, 100 \mathrm{~mm} \times 4 \mathrm{~mm})$ (Phenomenex, USA) in reversed phase and isocratic elution. Individual antibiotic compound and a mixture of standards were detected at $230 \mathrm{~nm}$ using UV detector. The mobile phase contained a combination of $0.05 \mathrm{M}$ $\mathrm{Na}_{2} \mathrm{HPO}_{4}$, acetonitrile and methanol (70:10:20) at pH 8 . The mobile phase was pumped from the reservoir to the column at a flow rate of $1 \mathrm{~mL} \mathrm{~min}{ }^{-1}$. The column thermostat was set at $40{ }^{\circ} \mathrm{C}$ and the injection volume was $20 \mu \mathrm{L}$. All the seven standard compounds were eluted within $14 \mathrm{~min}$.

\section{Preparation of standard stock solution}

The stock standard solutions $\left(1000 \mu \mathrm{g} \mathrm{mL}^{-1}\right)$ were prepared individually for the selected seven drug standards by weighing $10 \mathrm{mg}$ of reference standard substances and dissolving them in 1:1 mL of methanol:deionized water $(\mathrm{v} / \mathrm{v})$ in $10 \mathrm{~mL}$ volumetric flask. The stock solutions were stored at $-18{ }^{\circ} \mathrm{C}$ and prepared fresh every 1 month. Mixed stock solutions of the seven antibiotic standards $\left(200 \mu \mathrm{g} \mathrm{mL}^{-1}\right)$ and the series of working standard solutions for the method development were prepared daily with a mobile phase dilution.

All the standard solutions prepared for the LC were filtered through a $0.45 \mu \mathrm{m}$ nylon syringe membrane filter before use. The mobile phase was filtered through the Millipore glass filter (Millipore filter cellulose nitrate gridded with $0.22 \mu$ size and $47 \mathrm{~mm}$ diameter) assembly attached with vacuum pump and was sonicated with ultrasonic machine, B5510J-DTH (Branson, Danbury, $\mathrm{CT}$ ), for $30 \mathrm{~min}$ before pumping into HPLC system for degassing.

\section{Calibration standard solutions}

Five calibration standard solutions of $0.05,0.5,1,1.5$ and $2 \mu \mathrm{g} \mathrm{mL} \mathrm{m}^{-1}$ were prepared from their working stock solutions $\left(200 \mu \mathrm{g} \mathrm{mL}^{-1}\right)$, by transferring the appropriate aliquot and bringing the total volume to $10 \mathrm{~mL}$ using mobile phase dilution for the method development. Instrument blanks were prepared by placing a portion of the acetonitrile/methanol (10:20 ratio) solution used for sample reconstitution in an amber auto sampler vial for the instrumental analysis.

\section{Sampling}

Large-scale commercial poultry farms, village broiler and chicken egg producers are distributing the poultry products within the urban and peri-urban area of the capital city of Ethiopia, Addis Ababa. Across the city, poultry markets of various structures ranging from dayold chicks, retail eggs, slaughtered and frozen chicken markets as well as live poultry wholesaler do exist. Ten chicken samples (comprising 10 pieces each of liver, kidney and muscle) purchased from randomly selected supermarkets in Addis Ababa in October 2020 for antibiotic residue analysis. The samples were slaughtered and market-ready matured chickens that were prepared to vend for consumers in the supermarkets. After arrival at the laboratory, the samples were stored at $-20{ }^{\circ} \mathrm{C}$ until analysis. Addis Ababa (AA) was chosen as sampling site because of most of the markets, supermarkets and consumers are found in this city (since AA has much higher population compared to the other cities, and have more consumption of chickens than other cities).

\section{Sample preparation}

The selected veterinary antibiotics were extracted from the chicken tissue using the method reported by Lopes et al. [31] and Bousova et al. [32] with a slight modification (Fig. 1). Chicken tissue samples were homogenized and ground in a blender with dry ice to obtain uniformed sample and kept at $-20{ }^{\circ} \mathrm{C}$. Two grams tissue sample

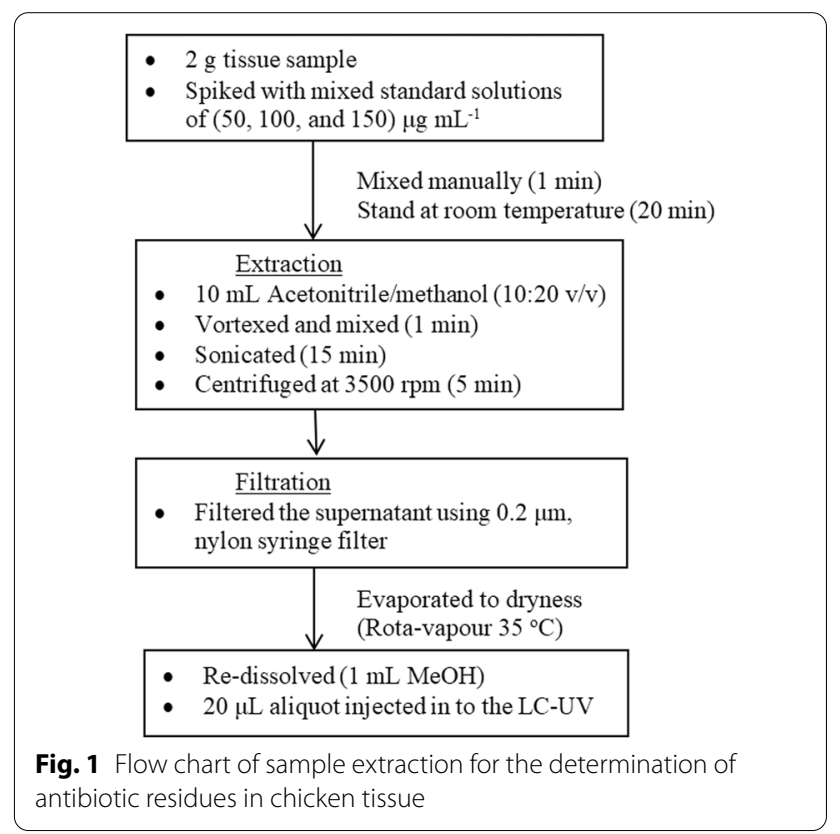


was placed in $50 \mathrm{~mL}$ poly-propylene centrifuge tube and spiked with mixed standard solutions. The spiked sample was homogenised by manual shaking for $1 \mathrm{~min}$ and left to stand at room temperature for $20 \mathrm{~min}$ to allow the equilibration of the antibiotics with the chicken matrix before their extraction. In order to precipitate the proteins and extraction of analytes, $10 \mathrm{~mL}$ extraction solvent, acetonitrile/methanol (10:20 ratio $\mathrm{v} / \mathrm{v})$ were added to the mixture, homogenized via vortexing at $1000 \mathrm{rpm}$ for $1 \mathrm{~min}$ and sonicated for $15 \mathrm{~min}$. Then, the mixtures were centrifuged for $5 \mathrm{~min}$ at $3500 \mathrm{rpm}$, the top clear supernatant was transferred using syringe filter $(0.2 \mu \mathrm{m}$, nylon) into $1 \mathrm{~mL}$ flask (Pyrex standard taper stopper), and evaporated to dryness using rotary evaporator at $35{ }^{\circ} \mathrm{C}$. The obtained dried or concentrated residues were re-dissolved with $1 \mathrm{~mL} \mathrm{MeOH}$ and $20 \mu \mathrm{L}$ aliquot was injected in to the LC-UV system for analysis without filtration. All the analyses were carried out in triplicate.

Matrix-match (negative concentration) solutions were prepared from drug-free samples that have the same biological matrices as the real chicken tissue samples. Matrix-match solutions were used as the blank matrix for the method validation to validate the specificity of the method and to ensure or control that no carryover or matrix effects were present. The sample preparation procedures for negative samples were according to the method mentioned above without antibiotic standards.

\section{Parameter optimization}

For the simultaneous detection method development, different factors that are affecting the separation processes were optimized. The parameters optimized include: $\mathrm{pH}$, flow rate, organic mobile phases (types of solvent, concentration and composition), and the absorption wavelengths. The mixed standard solution was scanned in the wavelength region of $200-400 \mathrm{~nm}$ for proper separation. The effect of mobile phase on flow rate was also investigated using a different flow rate of $0.5,1$ and $1.2 \mathrm{~mL} \mathrm{~min}^{-1}$. The chromatographic parameters were evaluated by taking both the resolution and symmetry of the peaks into account.

\section{Results and discussion}

\section{Selection of the type and volume of mobile phase}

The chicken tissue was chosen for the method optimization and validation procedures because it is the most frequently consumed tissue with the highest content of proteins in the world [33]. Hence selection of appropriate mobile phase is an important step to get good separation. The mobile phase solvent type and composition was selected according to the physicochemical properties of antibiotic drugs (such as polarity, solubility, $\mathrm{pK}_{\mathrm{a}}$ and miscibility with the aqueous phase) $[29,30]$. The $\mathrm{pK}_{\mathrm{a}}$ value is one of the main properties of an electrolyte that determines its chemical behaviour in solutions. Since most of the drugs are either weak acids or weak bases, they exist in both ionized and non-ionized forms depending on the $\mathrm{pH}$ of the solutions. Antibiotics are easily decomposed under strongly acidic or basic conditions by hydrolysis. Therefore, a suitable elution solvent should be carefully selected in order to achieve the highest recovery of the antibiotics contained in the tissue samples [34]. Therefore, preliminary experiments were performed using a hypersil BDS-C18 column $(3 \mu \mathrm{m}, 100 \mathrm{~mm} \times 4 \mathrm{~mm})$ for the selection of the type and volume of mobile phase.

Based on the reported literature, antibiotics have usually been separated on a reverse-phase column using acidic or basic mobile phases [35, 36]. The initial composition of the mobile phase was set at water-MeOH (75:25, $\mathrm{v} / \mathrm{v})$ to promote the retention of the most polar analytes. Then, due to the large number of analytes and their different affinities for the column, several elution programs and different ratios of water/acetonitrile with formic acid $(0.1 \%)$ as eluent were tested for mobile phase efficiency of the target analytes under this study. The chromatograms obtained did not satisfactorily resolve all the signals. Resolution of the compounds was clearly affected by the acidity of the mobile phase. To prevent this, formic acid was replaced with phosphate buffer, and $\mathrm{pH}$ was adjusted to 8 . A series of experiments were performed under the same experimental conditions and different types of phosphate buffers (i.e., sodium and potassium phosphate, citrate-phosphate buffer or Mcllvaine buffer) in a different concentration and composition with methanol and acetonitrile. By taking consideration of both the resolution and symmetry of the peak into account, $\mathrm{Na}_{2} \mathrm{HPO}_{4}$ at the concentration of $0.05 \mathrm{M}$ yielded the best resolution. Therefore, potassium phosphate and citrate-phosphate were ruled out and di-sodium phosphate was selected for further experiments.

To evaluate the effect of the volume and composition of organic solvents, a ratio of 30:30, 20:30, 15:25, and 10:20 $\mathrm{v} / \mathrm{v}$ acetonitrile and methanol were studied. The ratios of acetonitrile to methanol volume at 10:20 in combination with $0.05 \mathrm{M} \mathrm{Na}_{2} \mathrm{HPO}_{4}$ give good resolution between analytes. Therefore, mobile phase comprised three solvent composition in a combination of $0.05 \mathrm{M} \mathrm{Na}_{2} \mathrm{HPO}_{4}$, acetonitrile and methanol (70:10:20) were found optimum for this experiment.

\section{Wavelength selection}

The absorbance of a compound depends on the type of solvent, concentration and molar absorptivity (Beer's law). The individual absorbance maxima for the targeted antibiotics ranged from 210 to $290 \mathrm{~nm}$ based on the literature review [37-40] but a fixed wavelength was 


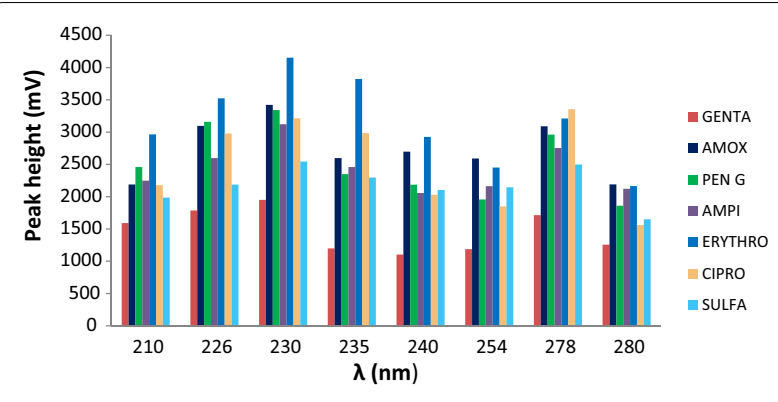

Fig. 2 Detector response of seven selected antibiotic drugs analysed using eight different UV wavelengths $(210,226,230$, $235,240,254,278$ and 280$) \mathrm{nm}$ to enable selection of the optimal wavelength based on the optimized parameters, mobile phase: 0.05 $\mathrm{Na}_{2} \mathrm{HPO}_{4}: \mathrm{ACN}: \mathrm{MeOH}$ (70:10:20), $\mathrm{pH}$ 8, temperature: $40{ }^{\circ} \mathrm{C}$ and flow rate: $1 \mathrm{~mL} \mathrm{\textrm {min } ^ { - 1 }}$

used to monitor the mixed multi-component eluate. In mobile phase composition of $0.05 \mathrm{M} \mathrm{Na}_{2} \mathrm{HPO}_{4}$, acetonitrile and methanol (70:10:20), $20 \mu \mathrm{L}$ mixed standards were injected at several UV wavelengths: $210,226,230$, 235, 240, 254, 278 and $280 \mathrm{~nm}$. From this investigation, the result showed that $230 \mathrm{~nm}$ yielded the largest overall relative peak height and peak area for all the analytes compared to those obtained at other wavelengths as can be seen in Fig. 2. The resulted maximum absorbance was different for each analyte. For example, three compounds (amoxicillin, ampicillin and penicillin G) give maximum UV absorption at 210 and $230 \mathrm{~nm}$. The other four (erythromycin, gentamicin, sulfamethoxazole and ciprofloxacin) showed a good absorbance at 210, 226, 235 and $278 \mathrm{~nm}$, respectively. However, Fig. 2 shows that erythromycin, gentamicin, ciprofloxacin, and sulfamethoxazole also have a maximum UV absorption at $230 \mathrm{~nm}$ comparatively with $210,226,235$ and $278 \mathrm{~nm}$ which have maximum absorbance for each analytes. This is because the absorbance of a compound depends on the type of solvent, concentration, molar absorptivity and the effect of the other compounds present in the mixture. Therefore, $230 \mathrm{~nm}$ was selected as an optimum wavelength at which all the seven compounds showed good absorbance.

\section{Optimization of $\mathrm{pH}$}

In the present work, studies involve only one variant at a time by keeping others as constant. The $\mathrm{pH}$ value is important as it affects the ionization status as well as the solubility of the analytes [41]. For efficient extraction of ionisable and relatively polar compounds, $\mathrm{pH}$ of the sample solution plays a key role. The $\mathrm{pH}$ of buffer or the mobile phase should be lower than two $\mathrm{pH}$ units below its $\mathrm{pK}_{\mathrm{a}}$ value to obtain the target analytes in their unionized forms so that they have a higher tendency to partition into the organic phase [42]. In this study, the effect of $\mathrm{pH}$ was investigated by varying the $\mathrm{pH}$ from 3 to 8.4 using orthophsphoric acid and sodium hydroxide solution. The highest peak areas of the target antibiotics were obtained at $\mathrm{pH} 8$ followed by a steady state in the range of (8-8.2) as can be seen in Fig. 3. Therefore, a mobile phase solution of $\mathrm{pH} 8$ was chosen as the optimum extraction condition.

\section{Flow rate optimization}

The mobile phase speed for mixed standards were checked out at different flow rates $(0.5-1.5) \mathrm{mL} \mathrm{min}^{-1}$ and the result obtained using $1 \mathrm{~mL} \mathrm{~min}^{-1}$ gave better resolution than others. This may be due to the interaction of the compound with the stationary and the mobile phase; a faster mobile phase flow limits the interaction of analyte with the stationary phase. It was observed that the increase in flow rate $\left(1.2 \mathrm{~mL} \mathrm{~min}^{-1}\right)$ decreases the retention time of all analyte compounds; and it adversely affected the resolution of some compounds. While decreasing the flow rate $\left(0.5 \mathrm{~mL} \mathrm{~min}^{-1}\right)$ increases the retention times and total run time, it caused and leads to broadening of the peaks and yielded poorly resolved peaks, in addition it is time consuming to get all peaks to appear, 17 min and more time is needed and more mobile phase amount consumed due to long time run. The optimum flow rate providing maximum sensitivity and the best analyte separation was $1.0 \mathrm{~mL} \mathrm{~min}^{-1}$ as shown in Fig. 4. Based on the above optimized conditions, the selected parameters that are suitable for the present work on method development were: mobile phase: $0.05 \quad \mathrm{Na}_{2} \mathrm{HPO}_{4}$ : ACN:MeOH (70:10:20) (v/v/v), temperature: $40{ }^{\circ} \mathrm{C}$, wavelength: $230 \mathrm{~nm}$, and flow rate: $1 \mathrm{~mL} \mathrm{~min}^{-1}$.

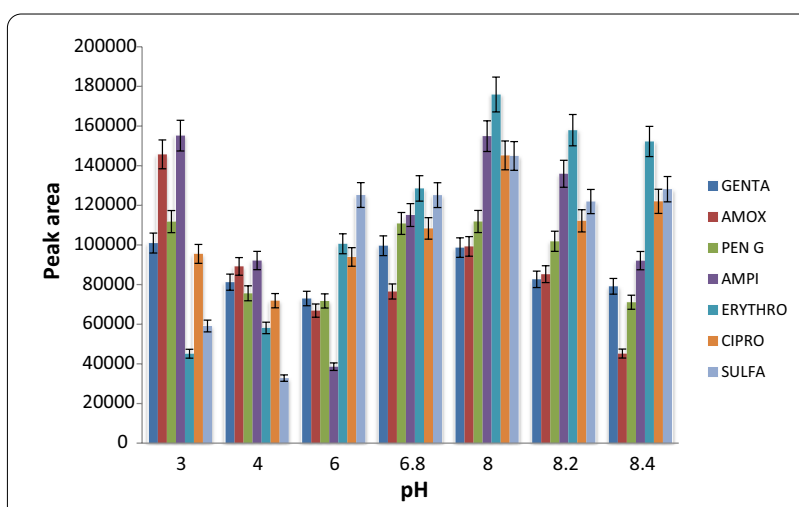

Fig. 3 The effect of pH of the mobile phase to peak areas on the determination of analytes based on the optimized parameters, mobile phase: $0.05 \mathrm{Na}_{2} \mathrm{HPO}_{4}: \mathrm{ACN}: \mathrm{MeOH}$ (70:10:20), temperature: $40{ }^{\circ} \mathrm{C}$, wavelength: $230 \mathrm{~nm}$, and flow rate: $1 \mathrm{~mL} \mathrm{\textrm {min } ^ { - 1 }}$ 

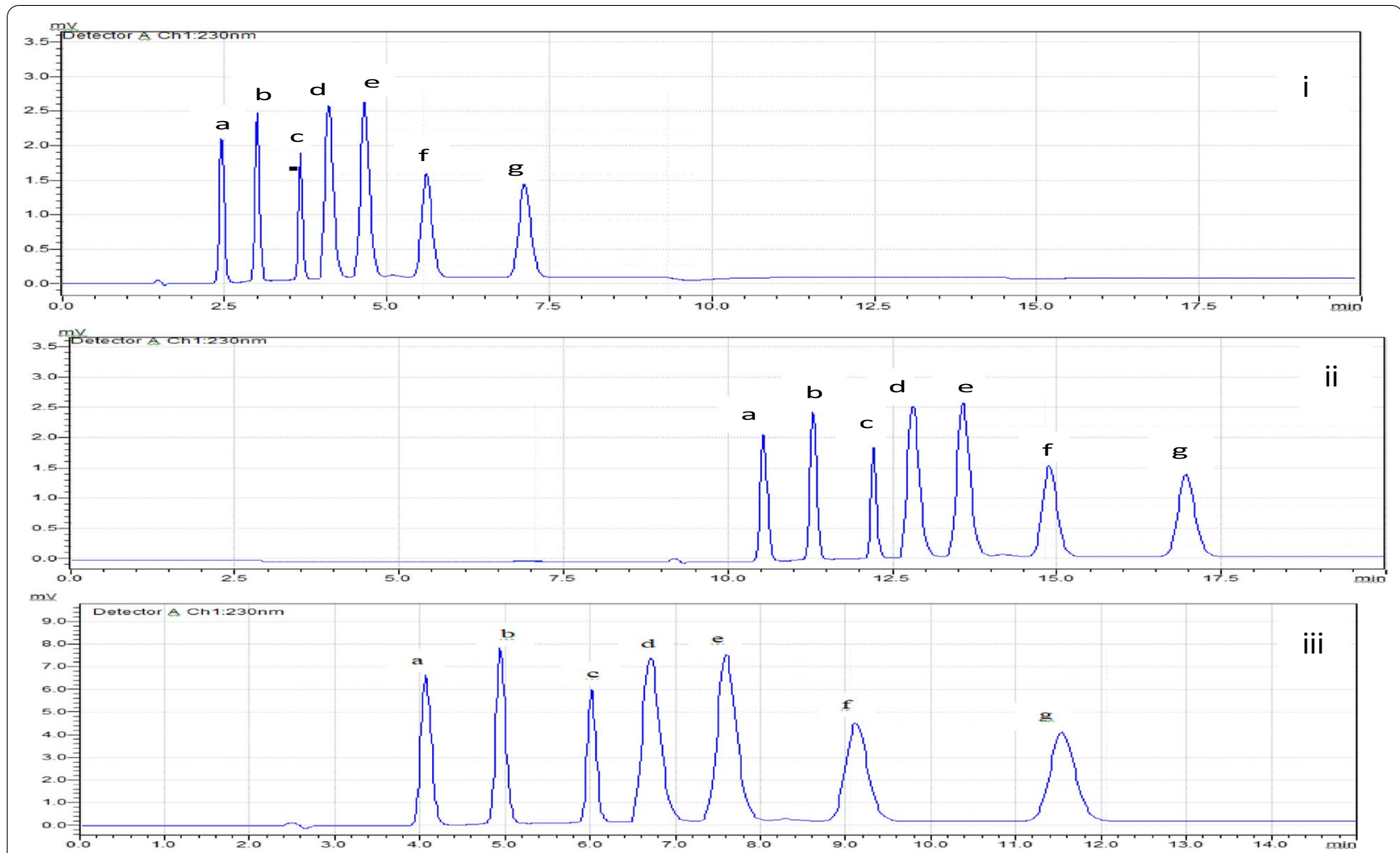

${ }^{a}$ (Gentamycin), $\quad{ }^{b}$ (Erythromycin), $\quad{ }^{c}$ (Amoxicillin), $\quad{ }^{d}$ (Ciprofloxacin), $\quad{ }^{e}$ (Ampicillin)

${ }^{f}$ ( Sulfamethoxazole) and ${ }^{g}$ (Pencillin $\left.G\right)$

Fig. 4 Chromatograms obtained using different mobile phase flow rates i $1.2 \mathrm{~mL} \mathrm{~min}^{-1}$, ii $0.5 \mathrm{~mL} \mathrm{~min} \mathrm{~m}^{-1}$ and iii $1.0 \mathrm{~mL} \mathrm{~min}^{-1}$. The mixed standard chromatogram results found based on the optimized parameters, mobile phase: $0.05 \mathrm{Na}_{2} \mathrm{HPO}_{4}: \mathrm{ACN}^{\mathrm{MeOH}}(70: 10: 20), \mathrm{pH}$, temperature: $40^{\circ} \mathrm{C}$, wavelength: $230 \mathrm{~nm}$, and flow rate: $1 \mathrm{~mL} \mathrm{\textrm {min } ^ { - 1 }}$

\section{Column temperature}

The column temperature is an important parameter as it affects the stability status of antibiotics. Each antibiotic has different stability behavior at different temperatures, most antibiotic molecules decomposed or degraded with increases in temperature $[43,44]$. The influences of the column temperature were investigated, by varying the temperature from 25 to $42{ }^{\circ} \mathrm{C}$ using LC solution software which controls the column temperature. At ambient temperature $\left(25^{\circ} \mathrm{C}\right)$, the responses were low for the selected components, as shown in Fig. 5, the column temperature at $40{ }^{\circ} \mathrm{C}$ was found to be the optimal setting, yielding the highest resolution, the greatest number of separated peaks and the strongest analyte response in combination with the above optimized mobile phase composition.

It should be noted that temperature can affect the separation of components. Many times this causes all of the analytes to come out sooner from the column, causing a reduction in the retention time $[45,46]$. Changes in resolution are due to changes in peak separation and/

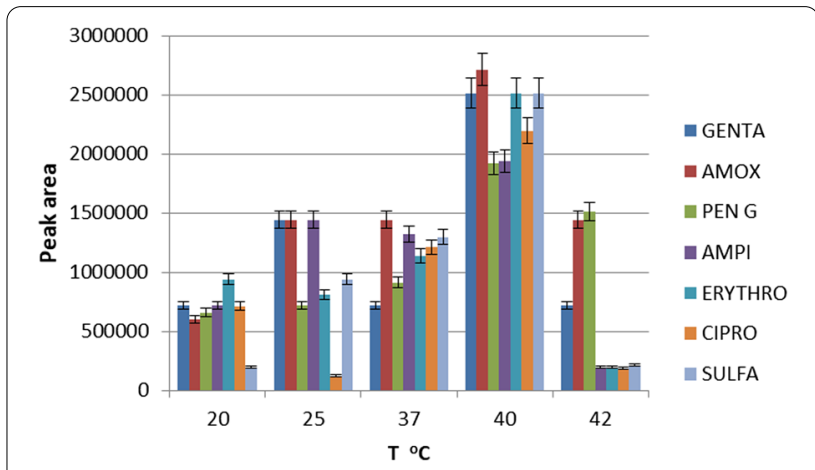

Fig. 5 Detector response for column temperature variation, by keeping other variables constant and optimized, mobile phase: 0.05 $\mathrm{Na}_{2} \mathrm{HPO}_{4}: \mathrm{ACN}: \mathrm{MeOH}$ (70:10:20), pH 8, wavelength: $230 \mathrm{~nm}$, and flow rate: $1 \mathrm{~mL} \mathrm{~min}^{-1}$

or peak width. Decreasing column temperatures usually increase peak separation but often with a corresponding increase in peak width. If the increase in peak separation 
is greater than the increase in peak width, improved peak resolution occurs. Therefore, a proper column temperature control is essential for separations with marginal resolution of the critical peak pair. In most applications, antibiotic residue separation was done at about $40{ }^{\circ} \mathrm{C}$ to manage this significant effects from back pressure and temperature.

\section{Injection volume}

In order to evaluate the maximum injection volume, some experiments were carried out by increasing the injection volume to 10,20 and $50 \mu \mathrm{L}$. Injection volume $10 \mu \mathrm{L}$ give small peak height. For larger injection volumes $(50 \mu \mathrm{L})$, the more polar compounds did not show linearity of response with concentration, possibly due to the overload of the column. For example, gentamicin and erythromycin, which are more polar than the other compounds, did not show linearity response for larger injection volume $50 \mu \mathrm{L}$. Injection volume $20 \mu \mathrm{L}$ was the optimum for this experiment and it is the maximum tolerable volume for the LC-UV system.

\section{Validation of the developed method}

The developed method for the determination of selected antibiotics was validated according to the rules of the Commission Decision 2002/657/EC [28] that establish the validation guidelines and general and numeric criteria for evaluation of fitness of a method for residue analysis. The parameters were evaluated for, linearity, sensitivity, precision, accuracy, specificity, robustness, system suitability, $C C \alpha$ (decision limit) and $C C \beta$ (detection capability) using both blank and spiked tissue samples at various concentrations.

\section{Standard calibration plots}

The calibration plots define the relationship between the detector response and the concentration of analyte in the sample matrix. For multiple analytes, a sample calibration plot was generated for each analyte [47]. The calibration plots were constructed by plotting the response ratio (ratio between peak area of antibiotic standards used on the $\mathrm{x}$-axis and peak area of found concentration or response on the y-axis) in $\left(\mu \mathrm{g} \mathrm{mL}^{-1}\right)$. The calibration plot indicated a linear relationship between response ratio and antibiotic standard concentration with an acceptable correlation coefficient and regression parameters as summarized in Fig. 6. The method linearity was investigated in the concentration range of $(0.05-150) \mu \mathrm{g} \mathrm{mL}^{-1}$.
The linearity was studied for all the test antibiotics under optimised conditions and extended up to $300 \mu \mathrm{g} \mathrm{mL}{ }^{-1}$ for erythromycin.

\section{Sensitivity}

Calibration plots for each antibiotic with the respective correlation coefficient were calculated by least squares linear regression analysis of the peak area ratio of each analytes. The calculations for the limits of detection (LOD) were based on the standard deviation of the response and slope (S), of the calibration curve of antibiotic compounds y-intercepts of using the equation $\mathrm{LOD}=3.3 \times \sigma / \mathrm{S}$. Limits of quantitation (LOQ) were calculated by the equation $\mathrm{LOQ}=10 \times \sigma / \mathrm{S}$ (Guidance for Industry Q2(R1), ICH, 2005) [48], where $\sigma$ is the standard deviation of the response and $\mathrm{S}$ the slope of the calibration curve. The results are reported in Table 2 which shows that the LODs ranged from 0.098 to $0.255 \mu \mathrm{g} \mathrm{mL}^{-1}$ and the LOQs from 0.297 to $0.574 \mu \mathrm{g} \mathrm{mL}^{-1}$.

\section{Selectivity}

The selectivity of the procedure in terms of the absence of interference compounds was checked by analysing drugfree and spiked samples of chicken tissue. The analysis was performed with optimized method and all the samples were checked for any interference at the retention times of the examined antibiotics at $230 \mathrm{~nm}$. No endogenous compounds were found to interfere with examined antibiotics as shown in Fig. 7, the typical chromatograms of blank and spiked tissue samples have a good response and resolution for the targeted components of the selected seven antibiotics.

\section{Specificity}

Specificity is the ability of the analytical method to distinguish between the analyte(s) and the other components in the sample matrix [49]. In order to investigate the specificity of the method for the interference components at the working wavelength, blank and matrixmatch (drug-free) chicken tissue samples were scanned from 200 to $800 \mathrm{~nm}$, the chromatograms are shown in Fig. 7. There was no interference peak observed in blanks and matrix-match tissue samples at the working wavelength of $230 \mathrm{~nm}$. Therefore, the method presented in this study is specific for determination of the seven antibiotic compounds. Furthermore, non-interfering peaks appeared in the chromatogram of the spiked antibiotics retention times, the purities of the investigated peaks

(See figure on next page.)

Fig. 6 Calibration plots of the selected seven antibiotics with regression equation and correlation coefficient for each of the seven selected antibiotics based on the optimized parameters; mobile phase: $0.05 \mathrm{Na}_{2} \mathrm{HPO}_{4}: \mathrm{ACN}^{\mathrm{MeOH}}(70: 10: 20)$, $\mathrm{pH}: 8$, temperature: $40{ }^{\circ} \mathrm{C}$, wavelength: 230 nm, flow rate: $1 \mathrm{~mL} \mathrm{~min}^{-1}$; a Gentamycin, b Erythromycin, c Amoxicillin, d Ciprofloxacin, e Ampicillin, f Sulfamethoxazole, $\mathbf{g}$ Penicillin G; The significance of independent factors was determined using Fisher's statistical test for analysis of the variance (ANOVA) model 


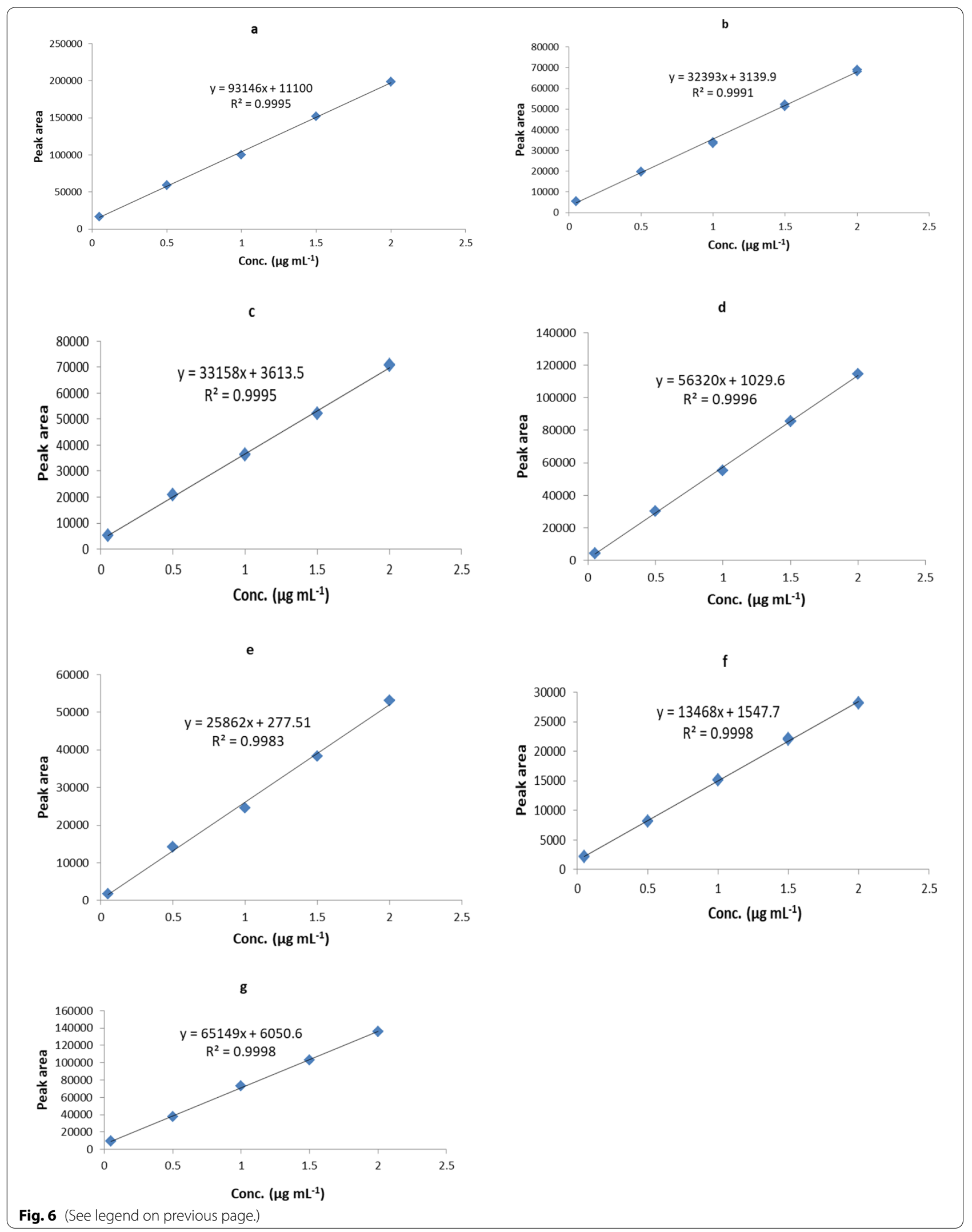


Table 2 Precision and sensitivity data of the seven examined antibiotics

\begin{tabular}{|c|c|c|c|c|c|c|}
\hline \multirow[t]{2}{*}{ ID } & \multirow[t]{2}{*}{ Antibiotics } & \multirow[t]{2}{*}{ LOD } & \multirow[t]{2}{*}{ LOQ } & \multirow[t]{2}{*}{ \%Recovery } & \multicolumn{2}{|l|}{ Precision in \% RSD } \\
\hline & & & & & $\begin{array}{l}\text { Repeatability (\% RSD, } \\
\mathrm{n}=3 \text { ) }\end{array}$ & $\begin{array}{l}\text { Reproducibility } \\
(\% \mathrm{RSD}, \mathrm{n}=3)\end{array}$ \\
\hline a & Gentamycin & 0.146 & 0.442 & 99.1 & 1.1 & 1.1 \\
\hline$b$ & Erythromycin & 0.098 & 0.297 & 107 & 1.2 & 1.1 \\
\hline c & Amoxicillin & 0.137 & 0.416 & 101 & 2.4 & 4.0 \\
\hline$d$ & Ciprofloxacin & 0.126 & 0.380 & 103 & 3.5 & 2.3 \\
\hline e & Ampicillin & 0.255 & 0.774 & 104 & 4.7 & 4.2 \\
\hline f & Sulfamethoxazole & 0.105 & 0.319 & 98.1 & 2.1 & 1.5 \\
\hline$g$ & Pencillin G & 0.189 & 0.574 & 98.6 & 4.2 & 4.6 \\
\hline
\end{tabular}

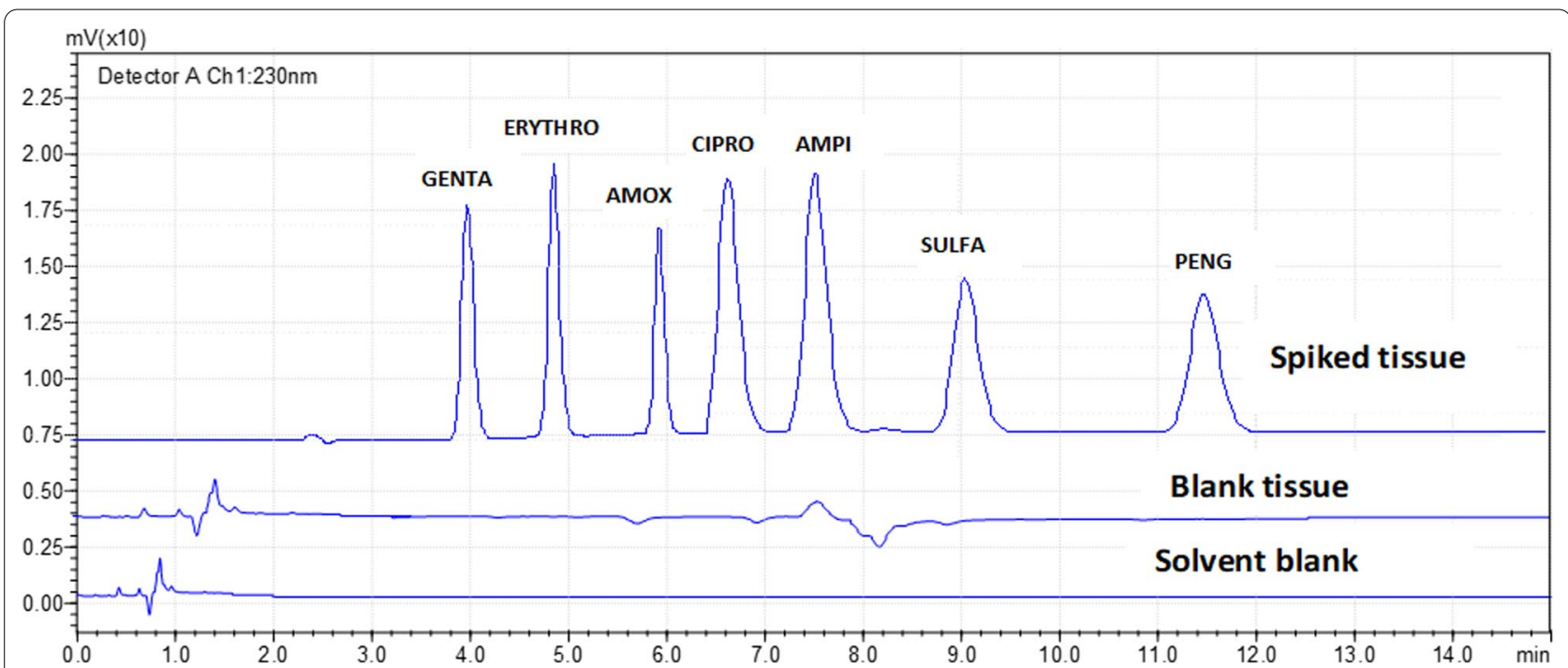

Fig. 7 Overlay chromatograms of blank and spiked tissue samples based on the optimized parameters, mobile phase: $0.05 \mathrm{Na} 2 \mathrm{HPO}_{4}: \mathrm{ACN}^{\mathrm{MeOH}}$ (70:10:20), pH 8, temperature: $40^{\circ} \mathrm{C}$, wavelength: $230 \mathrm{~nm}$ and flow rate: $1 \mathrm{~mL} \mathrm{~min}{ }^{-1}$

were all confirmed to be specific for the selected antibiotics on the optimized conditions.

\section{Precision}

The precision of the method was evaluated in terms of repeatability (intra-day precision) and intermediate or reproducibility (inter-day precision). Repeatability was evaluated according to the matrix-matched approach by analyzing spiked drug-free chicken tissue samples and injected in triplicate on the same day, under the optimum conditions at three concentrations of $0.5,1$, and 1.5 times the permitted limit according to the European Decision (European Commission Decision 2002/657/EC) [28]. Ampicillin, amoxicillin, and pencillin $\mathrm{G}$, have the MRL amount of $50 \mu \mathrm{g} \mathrm{kg}^{-1}$ and the spiked amount was $(25,50,75) \mu \mathrm{g}$ $\mathrm{kg}^{-1}$; ciprofloxacin, sulfamethoxazole, and gentamycin has MRL of $100 \mu \mathrm{g} \mathrm{kg}^{-1}$ and the spiked amount was $(50,100,150) \mu g \mathrm{~kg}^{-1}$; erythromycin has MRL of $200 \mu \mathrm{g} \mathrm{kg}^{-1}$ and the spiked amount was $(100,200$, 300) $\mu \mathrm{g} \mathrm{kg}^{-1}$. The maximum residue limit (MRL) of antibiotics in the food of animal origin was found from commission regulation (EU) $[17,50]$.

Intermediate precision was evaluated using a similar procedure, but the samples were analysed on six consecutive days and in all cases by triplicate analysis. The measured peak areas were used to calculate the percent relative standard deviations (\% RSDs) (Table 3). The result obtained for the precision study were regarded as acceptable for analysis, due to the small \% RSDs that ranged from 0.6 to $7.6 \%$, which were lower than the stipulated values of $15 \%$ [51]. 
Table 3 Intra-day precision, inter-day precision and recovery studies of the developed method for the determination of antibiotics in chicken tissue

\begin{tabular}{|c|c|c|c|c|c|c|c|}
\hline \multirow[t]{2}{*}{ Analyte } & \multirow{2}{*}{$\begin{array}{l}\text { Spiked amount } \\
\mu \mathrm{kg}^{-1}\end{array}$} & \multicolumn{3}{|c|}{ Repeatability $^{\mathrm{a}}$ ( $\mathrm{n}=3$ determinations) } & \multicolumn{3}{|c|}{ Reproducibility $^{b}$ ( $n=3$ determinations) } \\
\hline & & $\begin{array}{l}\text { Measured } \pm S D \\
\left(\mu \mathbf{~ k g}^{-1}\right)\end{array}$ & $\%$ RSD & Recovery (\%) & $\begin{array}{l}\text { Measured } \pm \text { SD } \\
\left(\mu \mathbf{~ k g}^{-1}\right)\end{array}$ & $\%$ RSD & Recovery (\%) \\
\hline \multirow[t]{3}{*}{ GENTA } & 50 & $48.0 \pm 0.7$ & 3.0 & 94.4 & $50.5 \pm 2.5$ & 2.1 & 101 \\
\hline & 100 & $99.5 \pm 2.1$ & 1.1 & 99.0 & $99.8 \pm 1.4$ & 1.1 & 99.8 \\
\hline & 150 & $149 \pm 1.1$ & 1.3 & 99.2 & $147 \pm 1.2$ & 1.1 & 99.0 \\
\hline \multirow[t]{3}{*}{ AMOX } & 25 & $24.3 \pm 0.9$ & 3.7 & 97.2 & $24.8 \pm 1.3$ & 5.3 & 99.4 \\
\hline & 50 & $50.5 \pm 1.2$ & 2.4 & 101 & $49.5 \pm 2.0$ & 4 & 99.0 \\
\hline & 75 & $75.8 \pm 1.1$ & 1.4 & 101 & $75.7 \pm 1.8$ & 2.3 & 101 \\
\hline \multirow[t]{3}{*}{ PEN G } & 25 & $24.9 \pm 1.6$ & 6.3 & 99.6 & $23.9 \pm 1.8$ & 7.5 & 95.6 \\
\hline & 50 & $49.7 \pm 2.1$ & 4.2 & 99.4 & $50.3 \pm 3.8$ & 7.6 & 101 \\
\hline & 75 & $75.3 \pm 2.5$ & 3.3 & 100 & $76.3 \pm 3.0$ & 3.9 & 102 \\
\hline \multirow[t]{3}{*}{ AMPI } & 25 & $23.9 \pm 2.0$ & 3.3 & 96.0 & $23.5 \pm 0.3$ & 3.7 & 95.5 \\
\hline & 50 & $50.9 \pm 2.4$ & 4.7 & 102 & $51.1 \pm 2.1$ & 4.2 & 102 \\
\hline & 75 & $74.7 \pm 2.8$ & 1.3 & 101 & $74.9 \pm 1.1$ & 2.4 & 100 \\
\hline \multirow[t]{3}{*}{ ERYTHRO } & 100 & $99.4 \pm 1.7$ & 1.1 & 99.4 & $98.9 \pm 2.3$ & 1.5 & 98.9 \\
\hline & 200 & $200 \pm 3.5$ & 1.2 & 99.8 & $199 \pm 3.4$ & 1.1 & 99.3 \\
\hline & 300 & $299 \pm 3.9$ & 0.9 & 99.8 & $299 \pm 3.2$ & 0.7 & 99.0 \\
\hline \multirow[t]{3}{*}{ SULFA } & 50 & $47.0 \pm 0.8$ & 3.1 & 95.6 & $50.2 \pm 3.5$ & 2.4 & 101 \\
\hline & 100 & $99.9 \pm 2.3$ & 2.1 & 98.9 & $99.4 \pm 2.4$ & 1.5 & 99.3 \\
\hline & 150 & $149 \pm 1.7$ & 1.2 & 99.0 & $146 \pm 1.6$ & 1.3 & 97.0 \\
\hline \multirow[t]{3}{*}{ CIPRO } & 50 & $50.7 \pm 0.7$ & 1.4 & 101 & $49.8 \pm 1.0$ & 2.1 & 99.6 \\
\hline & 100 & $98.1 \pm 3.2$ & 3.5 & 98.7 & $101 \pm 1.1$ & 2.3 & 101 \\
\hline & 150 & $144 \pm 1.3$ & 1.1 & 94.0 & $142 \pm 1.3$ & 1.4 & 95.0 \\
\hline
\end{tabular}

${ }^{a}$ Studied by spiking the tissue samples on the same day, under the same experimental conditions

${ }^{b}$ Evaluated by spiking the indicated concentration levels in triplicate for six consecutive days

\section{Accuracy}

To study the accuracy of the proposed method, recovery studies were carried out by applying standard addition at different levels in $\mu \mathrm{g} \mathrm{kg}^{-1}$ to tissue sample. As reported in Table 3, the recoveries of the target compounds ranged from 94 to $102 \%$ for spiked tissue samples, which are within the acceptable range [51]. The result shows the optimized method was adequate for the simultaneous analysis of these antibiotics in practical chicken tissue samples.

\section{Robustness}

Robustness is typically assessed by the effect of small deliberate changes to chromatographic methods on system suitability parameters such as peak retention, resolution, and efficiency [52] and provides an indication of its reliability during application. Robustness of the developed method was investigated after minor modifications of conditions including changes to the flow rate of the mobile phase 0.8 and 1.2, variations to $\mathrm{pH}$ of mobile phase between 7.9 and 8.1, and analysis temperature between 38 and $42{ }^{\circ} \mathrm{C}$. The results in Table 4 revealed that the developed method is robust, and the peaks are well separated and elute with acceptable symmetry and resolution.

\section{System suitability}

The system suitability test of a chromatographic method is used to ensure the chromatographic system is adequate for application to samples. The parameters considered for this test includes retention time, resolution (to the adjacent peak), peak symmetry and number of theoretical plates [53]. These parameters were investigated using the optimized chromatographic conditions. The results met the acceptance criterion as listed in Table 5 and reflect good performance for all the selected analytes.

\section{Decision limit (CCa) and detection capability (CC $\beta$ )}

The decision limit and detection capability correspond to the regulation of the European Commission 2002/657/EG [28]. CCa (decision limit) is a non-conformity of the samples concluded, with an error probability $\alpha$ of $5 \%$, while CC $\beta$ (detectability) is defined as the smallest detectable content of the substance and/ 
Table 4 Effects of the analytical parameters change performed for robustness evaluation in flow rate, $\mathrm{pH}$ of mobile phase and temperature

\begin{tabular}{|c|c|c|c|c|c|c|c|c|c|c|}
\hline \multirow[t]{3}{*}{ Compounds } & \multicolumn{10}{|c|}{ Parameters changed for robustness study } \\
\hline & \multicolumn{4}{|c|}{ Flow rate $\left(\mathrm{mL} \min ^{-1}\right)$} & \multicolumn{3}{|c|}{ pH of mobile phase } & \multicolumn{3}{|c|}{ Analysis temperature ${ }^{\circ} \mathrm{C}$} \\
\hline & & 0.8 & 1.0 & 1.2 & 7.8 & 8.0 & 8.2 & 38 & 40 & 42 \\
\hline \multirow[t]{3}{*}{ GENTA } & Peak symmetry & 0.96 & 1.00 & 0.99 & 0.59 & 0.47 & 0.22 & 0.22 & 0.90 & 0.84 \\
\hline & $\%$ RSD & 1.14 & 3.33 & 2.15 & 1.96 & 1.96 & 3.02 & 2.43 & 3.10 & 3.10 \\
\hline & Rt (min) & 3.78 & 3.85 & 3.65 & 3.80 & 3.86 & 3.88 & 3.56 & 3.83 & 3.79 \\
\hline \multirow[t]{3}{*}{ AMOX } & Peak symmetry & 0.96 & 0.94 & 0.79 & 0.97 & 0.78 & 1.00 & 0.94 & 0.39 & 0.68 \\
\hline & $\%$ RSD & 3.27 & 2.54 & 3.70 & 0.22 & 1.24 & 4.32 & 2.37 & 2.88 & 1.25 \\
\hline & Rt (min) & 5.89 & 5.82 & 5.90 & 5.69 & 5.81 & 5.76 & 5.70 & 5.89 & 5.79 \\
\hline \multirow[t]{3}{*}{ PEN G } & Peak symmetry & 0.74 & 0.25 & 0.86 & 0.85 & 0.64 & 0.94 & 0.95 & 1.59 & 0.65 \\
\hline & $\%$ RSD & 4.57 & 3.26 & 2.37 & 2.15 & 1.28 & 0.26 & 1.24 & 1.24 & 0.27 \\
\hline & Rt (min) & 11.65 & 11.25 & 11.28 & 11.98 & 11.36 & 11.98 & 11.22 & 11.21 & 11.14 \\
\hline \multirow[t]{3}{*}{ AMPI } & Peak symmetry & 0.52 & 1.00 & 0.50 & 1.00 & 1.26 & 0.78 & 1.46 & 0.68 & 0.63 \\
\hline & $\%$ RSD & 2.43 & 3.27 & 1.25 & 5.32 & 4.24 & 6.32 & 1.24 & 4.24 & 1.98 \\
\hline & Rt (min) & 7.37 & 7.38 & 7.46 & 7.21 & 7.31 & 7.21 & 7.97 & 7.33 & 7.30 \\
\hline \multirow[t]{3}{*}{ ERYTHRO } & Peak symmetry & 1.25 & 0.95 & 0.95 & 1.15 & 1.09 & 1.74 & 0.22 & 0.84 & 0.68 \\
\hline & $\%$ RSD & 1.24 & 1.42 & 1.98 & 2.37 & 4.37 & 4.98 & 2.40 & 1.87 & 1.79 \\
\hline & Rt (min) & 4.75 & 4.75 & 4.80 & 4.72 & 4.71 & 4.75 & 4.69 & 4.76 & 4.60 \\
\hline \multirow[t]{3}{*}{ SULFA } & Peak symmetry & 0.99 & 0.99 & 1.00 & 1.00 & 0.61 & 0.67 & 0.42 & 0.90 & 0.47 \\
\hline & $\%$ RSD & 3.02 & 2.67 & 4.14 & 2.43 & 3.10 & 3.10 & 3.27 & 1.24 & 0.24 \\
\hline & Rt (min) & 8.80 & 8.82 & 8.86 & 8.81 & 8.75 & 8.12 & 8.54 & 8.85 & 8.13 \\
\hline \multirow[t]{3}{*}{ CIPRO } & Peak symmetry & 0.91 & 0.59 & 0.22 & 1.04 & 1.00 & 0.91 & 0.91 & 0.59 & 0.22 \\
\hline & $\%$ RSD & 3.04 & 1.32 & 3.26 & 2.65 & 3.12 & 2.37 & 1.24 & 3.26 & 3.01 \\
\hline & Rt (min) & 6.50 & 6.55 & 6.24 & 6.56 & 6.70 & 6.28 & 6.45 & 6.12 & 6.25 \\
\hline
\end{tabular}

Table 5 System suitability results determined for the developed chromatographic method

\begin{tabular}{|c|c|c|c|c|}
\hline Compound & Retention time ( $\mathrm{min}$ ) & Resolution & Peak symmetry & Theoretical plates $(\mathrm{N})$ \\
\hline Gentamycin & 3.851 & 2.39 & 0.986 & 112,263 \\
\hline Erythromycin & 4.752 & 8.52 & 0.875 & 214,489 \\
\hline Amoxicillin & 5.822 & 3.69 & 0.884 & 152,353 \\
\hline Ciprofloxacin & 6.554 & 3.25 & 0.657 & 321,443 \\
\hline Ampicillin & 7.382 & 2.98 & 0.793 & 432,008 \\
\hline Sulfamethoxazole & 8.824 & 15.23 & 0.642 & 122,443 \\
\hline Pencillin G & 11.252 & 14.36 & 0.527 & 413,963 \\
\hline Reference values [53] & & $>1.5$ & $>0.50$ & $>13,333$ (2000/column) \\
\hline
\end{tabular}

or quantified in a sample with an error probability $\beta$ of $5 \%$ ( $1 \%$ for prohibited substances). CC $\alpha$ is calculated by analyzing blanks spiked with the analyte at the MRL or by using the calibration curve procedure in accordance with ISO 11843 from the data obtained during the validation of the method. $\mathrm{CC} \beta$ is calculated from the $\mathrm{CC} \alpha$ value and the standard deviation at that concentration. For substances with MRLs, the decision limit and detection capability must be greater than the MRL, the values of $\alpha$ and $\beta$ errors must be less than or equal to $5 \%$.

The determination of these parameters was obtained by the analysis and extraction of five blank samples spiked at levels of concentration at their MRL level. In order to complete the validation procedure for tissue samples, the decision limit CC $\alpha(\alpha=5 \%)$ were calculated as the mean values of the found concentrations at the permitted limit plus 1.64 times the corresponding standard deviations. 
Table 6 The values of (decision limit) CCa and (detection capability) CC $\beta$ for chicken tissue at the MRL enacted by the EU

\begin{tabular}{|c|c|c|c|c|c|c|c|}
\hline Analyte & $\begin{array}{l}\text { Added } \\
\left(\mu \mathrm{kg}^{-1}\right)\end{array}$ & $\begin{array}{l}\text { Found } \pm S D \\
\left(\mu \mathrm{kg}^{-1}\right)\end{array}$ & $\begin{array}{l}\text { Error a } \\
(1.64 \times S D)\end{array}$ & $\mathrm{CCa}\left(\mu \mathrm{g} \mathrm{kg}{ }^{-1}\right)$ & $\begin{array}{l}\text { Found } \pm \text { SD } \\
\left(\mu \mathbf{~ k g}^{-1}\right)\end{array}$ & $\begin{array}{l}\text { Error } \beta \\
(1.64 \times S D)\end{array}$ & $\mathrm{CC} \beta\left(\mu \mathrm{g} \mathrm{kg}^{-1}\right)$ \\
\hline GENTA & 100 & $99.5 \pm 2.1$ & 3.44 & 103 & $99.8 \pm 1.4$ & 2.30 & 106 \\
\hline AMOX & 50 & $50.5 \pm 1.2$ & 1.97 & 52.0 & $49.5 \pm 2.0$ & 3.28 & 55.3 \\
\hline PEN G & 50 & $49.7 \pm 2.1$ & 3.44 & 53.4 & $50.2 \pm 2.1$ & 3.44 & 56.9 \\
\hline AMPI & 50 & $50.9 \pm 2.4$ & 3.94 & 53.9 & $51.1 \pm 2.1$ & 3.44 & 57.4 \\
\hline ERYTHRO & 200 & $200 \pm 3.0$ & 4.92 & 205 & $199 \pm 2.4$ & 3.94 & 209 \\
\hline SULFA & 100 & $99.9 \pm 2.3$ & 3.77 & 104 & $99.4 \pm 2.4$ & 3.94 & 108 \\
\hline CIPRO & 100 & $98.1 \pm 2.2$ & 3.61 & 104 & $101 \pm 1.1$ & 1.80 & 105 \\
\hline
\end{tabular}

$\mathrm{SD}=$ standard deviation

The detection capability $(C C \beta)(\beta=5 \%)$ was obtained by adding $C C \alpha$ values to 1.64 times the corresponding standard deviation of spiked tissue samples. Table 6 summarizes the obtained $C C \alpha$ and $C C \beta$ value for chicken tissue at their MRL level.

\section{Application of the method to real samples}

The method was developed and optimized using chicken tissue matrix-match samples which have the same biological matrix but without analyte. However in order to prove its applicability and to make the method suitable for performing routine analyses, it was further applied in real tissues and the organ meat of chickens (kidney and liver). Chicken samples purchased from five local supermarkets were analyzed for their antibiotic residue using the developed and validated method. Most of the samples analyzed were free from the target analytes, except for chicken samples from one supplier. In two chicken samples purchased from one supermarket, amoxicillin, ampicillin, penicillin $\mathrm{G}$ and sulfamethoxazole were detected in muscle tissue and organ meats at levels below established MRLs. Although the amounts detected were below limits of quantification, chicken organ meats (kidney and liver) observed to present consistently higher values of the detected analytes in comparison to the other tested muscle tissues. Ciprofloxacin, gentamycin and erythromycin were not detected in all the chicken samples.

\section{Conclusion}

A simple, accurate, precise and robust liquid chromatography with UV detection (LC-UV) method has been developed for the simultaneous determination of seven selected multi-residue, multiclass drugs in the chicken tissue using a single optimized condition. Chicken tissue was analyzed for the residues of seven antibiotic residues including gentamicin amoxicillin, ampicillin, ciprofloxacin, erythromycin, penicillin $\mathrm{G}$ and sulphamethoxazole. The developed method was validated using European Commission Decision 2002/657/EC guidelines, which proves the reliability of the proposed method. The accuracy of the method was validated by percentage recovery and found to be in the acceptable range. Analytical method development and validation are continuous and interconnected activities. The developed analytical method has many advantages; it has simple sample preparation procedure based on acetonitrile extraction of antibiotics in the food of animal origin, cost effective with less time separation, i.e., 14 min chromatographic run which allowed seven multiclass antibiotic residues analyses to be performed within one injection volume. The method validation parameters demonstrate its reliability, satisfactory recovery, precision, and good specificity provided good performance that was easily applied to the analysis of multiclass multi-residue analysis in chicken samples at $\mu \mathrm{g} \mathrm{mL}^{-1}$ levels. Furthermore, to the best of our knowledge, this is the first instance in which an analytical procedure for the simultaneous determination of these selected seven multiclass, multi-residue analysis using LC-UV from chicken tissue samples. This is a cost-effective and alternative with simple instrumentation approach for laboratories that lack highly specialized state-of-the-art instrumentation.

\section{Abbreviations}

AA: Addis Ababa; ADI: Acceptable daily intake; AMOX: Amoxicillin; AMPI: Ampicillin; ANOVA: Analysis of variance; CAC: Codex Alimentarius Commission; ACN Acetonitrile; CCa: Decision limit; CC $\beta$ : Detection capability; CIP: Ciprofloxacin; EFDA: Ethiopian Food and Drug Administration; EPHI: Ethiopian Public Health Institute; ERYTHRO: Erthyromycin; FAO: Food and Agriculture Organization; GC: Gas chromatography; GENTA: Gentamicin; HPLC: High performance liquid chromatography; HR-MS: High resolution-mass spectrometry; ICH Q2(R1): International Conference on Harmonisation for Registration of Pharmaceuticals for Human Use; LC-MS/MS: Liquid chromatography-tandem mass spectrometry; LC-QToFMS: Liquid chromatography-quadrupole time-of-flight mass spectrometry; (LC-QqQ-MS): Liquid chromatography-triple quadrupole-mass spectrometry; LC-UV: Liquid chromatography with ultraviolet detection; LOD: Limits of detection; LOQ: Limits of quantification; MRLs: Maximum residue limits; PEN G: Penicillin G; RSD: Relative standard deviation; SULFA: Sulfamethoxazole; WHO: World Health Organization.

\section{Acknowledgements}

The authors express their gratitude to the Ethiopian Public Health Institute for providing laboratory facilities and financial support for sampling. Aynalem 
Lakew would like to thank the Ethiopian Public Health Institutefor sponsoring her PhD study.

\section{Authors' contributions}

All the authors made significant contributions to the manuscript and agree to its publication. AL, NM, and BSC designed the study; AL, TA, and MW performed the experiments and collected the data; AL, NM, and BSC analyzed the data; AL drafted the manuscript; NM and BSC critically reviewed the manuscript. All the authors read and approved the final manuscript.

\section{Funding}

This research did not receive any financial support from any funding agency.

\section{Availability of data and materials}

The data sets used and analyzed during the study are available to readers as in the manuscript. There are no additional data with the authors. All the data are included in the manuscript.

\section{Declarations}

Ethics approval and consent to participate

Not applicable.

\section{Consent for publication}

Not applicable.

\section{Competing interests}

The authors declare that they have no competing interests.

\section{Author details}

1Ethiopian Public Health Institute, P. O. Box 1242/5654, Addis Ababa, Ethiopia. ${ }^{2}$ Department of Chemistry, College of Natural and Computational Sciences, Addis Ababa University, P. O. Box 1176, Addis Ababa, Ethiopia.

Received: 2 December 2021 Accepted: 9 February 2022

Published online: 21 February 2022

\section{References}

1. Samanidou V, Nisyriou S. Multi-residue methods for confirmatory determination of antibiotics in milk, review. J Sep Sci. 2016:31:2068-90.

2. Mirza MW, Rehman ZU, Mukhtar N. Use of organic acids as potential feed additives in poultry production. J World's Poult Res. 2016;6:105-16.

3. Hoelzer K, Wong N, Thomas J, Talkington K, Jungman E, Coukell A. Antimicrobial drug use in food-producing animals and associated human health risks: what, and how strong, is the evidence? BMC Vet Res. 2017;13:209-11.

4. Etebu E, Arikekpar I. Antibiotics: classification and mechanisms of action with emphasis on molecular perspectives. Int J Appl Microbiol Biotechnol Res. 2016;4:90-101.

5. Gothwal R, Shashidhar T. Antibiotic pollution in the environment, a review. Clean Soil Air Water. 2014:42:1-11.

6. Ture M, Fentie T, Regassa B. Veterinary drug residue: the risk, public health significance and its management. Vet Sci J. 2019;13:555-856.

7. Roth N, Hofacre C, Zitz U, Mathis GF, Moder K, Doupovec B, Berghouse R, Domig KJ. Prevalence of antibiotic-resistant E. coli in broilers challenged with a multi-resistant E. coli strain and received ampicillin, an organic acid-based feed additive or a synbiotic preparation. Poul Sci. 2019;98:2598-607.

8. Beyene T. Veterinary drug residues in food-animal products: its risk factors and potential effects on public health. J Vet Sci Technol. 2016;7:278-85.

9. Khatun R, Howlader AJ, Ahmed S, Islam N, Alam K, Haider S, Mahmud MS, Hasan MdA. Validation of the declared withdrawal periods of antibiotics. Univ J Pub Health. 2018;6:14-22

10. Beyene T, Tesega B. Rational veterinary drug use: Its significance in public health, review. J Vet Med Animal Health. 2014;6:302-8.

11. Tadesse T, Tadesse T. Public health impacts of antibiotic residues in foods of animal origin: a review. Pub Pol Admin Res. 2017;7:1-10.
12. Berghiche A, Khenenou T, Labiad I. A meta-analysis on antibiotic residues in meat of broiler chickens in developing countries. J World's Poult Res. 2019:9:89-97.

13. Rahman MA, Rahman AK, Islam MA, Alam MM. Antimicrobial resistance of Escherichia coli isolated from milk, beef and chicken meat in Bangladesh. Bangl J Vet Med. 2017;15:141-6.

14. World Health Organization (WHO). Evaluation of certain veterinary drug residues in food, 66th report joint FAO/WHO expert committee on food additives, WHO technical report series 939:18-32. World Health Organization, Geneva, Switzerland. 2006. https://apps.who.int/iris/handle/10665/ 43464. Accessed 31 Oct 2021.

15. FAO (Food and Agriculture Organization). Poultry Meat and Eggs Investment Centre Division, FAO Vialedelle Terme di Caracalla, Rome, Italy. 2010.

16. Codex Alimentarius Commission (CAC). Maximum Residue Limits for Veterinary Drugs in Foods. In: proceedings of the 35th session of the Codex Alimentarius Commission. 2012:40:1-40.

17. Smith R. Commission regulation (EU) No 330/2010. Core EU Legis. 2015. https://doi.org/10.1007/978-1-137-54482-7_12.

18. Parthasarathy R, Monette CE, Bracero S, Saha MS. Methods for field measurement of antibiotic concentrations: limitations and outlook, review. FEMS Microbiol Ecol. 2018;94:8-21.

19. Farre M, Kantiani L, Damia B. Analytical methodologies for the detection of $\beta$-lactam antibiotics in milk and feed samples. Trend Anal Chem. 2009:28:6-41.

20. Belal F, El-Enany N, Wahba MEK. Analytical methods for the determination of 4-quinolone antibacterials. Rev Anal Chem. 2017;36:25-35.

21. Gulyaev IV, Revelskii Al. Analyssis of pharmaceutical substances by reaction gas chromatography/mass spectrometry. J Anal Chem. 2010;65:1341-6.

22. Santos L, Ramos F. Analytical strategies for the detection and quantification of antibiotic residues in aquaculture fishes, a review. Trends Food Sci Technol. 2016;52:16-30.

23. Anumol T, Lehotay SJ, Stevens J, Zweigenbaum J. Comparison of veterinary drug residue results in animal tissues by ultrahigh-performance liquid chromatography coupled to triple quadrupole or quadrupoletime-of-flight tandem mass spectrometry. Anal Bioanal Chem. 2017:409:2639-53.

24. Besil N, Uclés S, Mezcúa M, Heinzen H, Fernández-Alba AR. Negative chemical ionization gas chromatography coupled to hybrid quadrupole time-of-flight mass spectrometry and automated accurate mass data processing for determination of pesticides in fruit and vegetables. Anal Bioanal Chem. 2015:407:6327-43.

25. Huang W, Qiu Q, Chen M, Shi J, Huang X, Kong Q, Long D, Chen Z, Yan S. Determination of 18 antibiotics in urine using LC-QqQ-MS/MS. J Chromatogr B. 2019;1105:176-83.

26. Freitas A, Barbosa J, Ramos F. Determination of amoxicillin stability in chicken meat by liquid chromatography-tandem mass spectrometry. Food Anal Methods. 2012;5:471-9.

27. Geib T, Sleno L, Hall RA, Stokes CS, Volmer DA. Triple quadrupole versus high resolution quadrupole-time-of-flight mass spectrometry for quantitative LC-MS/MS analysis of 25-hydroxy vitamin D in human serum. J Am Soc Mass Spectrosc. 2016;27:1404-10.

28. Commission Decision 2002/657/EC (12 August 2002) Implementing council directive 96/23/EC concerning the performance of analytical methods and the interpretation of results (notified under document number C. 3044. 2002.

29. O'Shea R, Moser HE. Physicochemical properties of antibacterial compounds: implications for drug discovery. J Med Chem. 2008;51:1-10.

30. Christopher AL, Lombardo F, BeryI WD, Paul JF. Experimental and computational approaches to estimate solubility and permeability in drug discovery and development settings, reviews. Adv Drug Del. 2012;64:4-17.

31. Lopes RP, Reyes RC, Gonzalez R, Vidal JLM, Frenich AG. Multi-residue determination of veterinary drugs in aquaculture fish samples by ultrahigh performance liquid chromatography coupled to tandem mass spectrometry. J Chromatogr B. 2012;895:39-47.

32. Bousova K, Senyuva H, Mittendorf K. Quantitative multi-residue method for determination antibiotics in chicken meat using turbulent flow chromatography. J Chromatogr A. 2013;1274:19-27.

33. Seong PN, Cho SH, Park KM, Kang GH, Park BY, Moon SS, Ba HV. Characterization of chicken by-products by mean of proximate and nutritional compositions. Korean J Food Sci. 2015;35:179-88. 
34. Dong MW, Boyes BE. Modern trends and best practices in mobilephase selection in reversed-phase chromatography. LCGC North Am. 2018;36(10):752-67.

35. Subirats $X$, Roses M, Bosch E. On the effect of organic solvent composition on the $\mathrm{pH}$ of buffered HPLC mobile phases and the $\mathrm{pK}_{\mathrm{a}}$ of analytes, a review. Sep Purif. 2007;36:231-55.

36. Veigurea R, Lossmanna K, Hecht M, Parmana E, Born R, Leitoa I, Herodesa K, Kipper K. Retention of acidic and basic analytes in reversed phase column using fluorinated and novel eluent additives for liquid chromatography-tandem mass spectrometry. J Chromatogr A. 2020;1613:460-667.

37. Cristina D, Oliveira C. Development of Micellar HPLC-UV method for determination of pharmaceuticals in water samples. J Anal Methods Chem. 2018;2018:12. https://doi.org/10.1155/2018/9143730.

38. Injac R, Ko N, Štrukelj B. Optimized method for determination of amoxicillin, ampicillin, sulfamethoxazole, and sulfacetamide in animal feed by micellar electrokinetic capillary chromatography and comparison with high-performance liquid chromatography. Croat Chem Acta. 2009:82:685-94

39. Tribut O, Tattevin P, Le TY, Michelet C. Simultaneous determination of 12-Lactam antibiotics in human plasma by high-performance liquid chromatography with UV detection: application to therapeutic drug monitoring. Antimicrob Agents Chemother. 2011;55:4873-9.

40. Mem H, Ma M. Development and validation of RP-HPLC method for determination of amoxicillin residues and application to NICOMAC coating machine. J Anal Pharm Res. 2018;7:586-94.

41. Shannon MM, Jeffrey LU, Amy LT, Richard JW. pH and temperature effects on the hydrolysis of three $\beta$-lactam antibiotics: ampicillin, cefalotin and cefoxitin. Sci Total Environ. 2014;466-467:547-55.

42. Bocian S, Krzemińska K. The separations using pure water as a mobile phase in liquid chromatography using polar-embedded stationary phases, review. Green Chem Lett. 2019;12:69-78.

43. Carstensen JT, Rhodes C. Drug stability: principles and practices. New York: Marcel Dekker Inc.; 2000.

44. Abbas RF, Hami HK, Mahdi NI. Removal of doxycycline hyclate by adsorption onto cobalt oxide at three different temperatures: Isotherm, thermodynamic and error analysis. Int J Environ Sci Technol. 2018;2018:1-8.

45. Martin J, Méndez R, Negro A. Effect of temperature on HPLC separations of penicillins. J Liquid Chromatogr. 1988;1 1:1707-16.

46. Hancock WS, Chloupek RC, Kirkland JJ, Snyder LR. Temperature as a variable in reversed-phase high-performance liquid chromatographic separations of peptide and protein samples. I. Optimizing the separation of a growth hormone tryptic digest. J Chromatogr A. 1994;686:31-43.

47. Saxena SK, Rangasamy R, Krishnan AA, Singh DP, Sumedh P, Uke SP, Malekadi RK, Sengar AS, Mohamed DP, Gupta A. Simultaneous determination of multi-residue and multiclass antibiotics in aquaculture shrimps by UPLC-MS/MS. Food Chem. 2018;1:1-23.

48. ICH. Harmonised tripartite guideline - validation of analytical procedures: test and methodology Q2 (R1) international conference on harmonisation of technical requirement for registration of pharmaceuticals for human use. 2005

49. Companyó R, Granados M, Guiteras J. Antibiotics in food legislation and validation of analytical methodologies. Anal Bioanal Chem. 2009:395:877-91.

50. CX/MRL 2-2018. Codex Alimentarius Commission—Maximum residue limits (MRLs) and risk management recommendations (RMRs) for residues of veterinary drugs in foods. 2018.

51. Belouafa S, Habti F, Benhar S, Belafkih B, Tayane S, Hamdouch S, Bennamara A, Abourriche A. Statistical tools and approaches to validate analytical methods: methodology and practical examples. Int J Metrol Qual Eng. 2017:8:1-9.

52. Dejaegher B, Heyden YV. Ruggedness and robustness testing, review. J Chromatogr A. 2007;1158:138-57.

53. Sharma MC, Sharma S. Micellar liquid chromatographic method development for determination and stability indicating of NelfinavirMesylate in pharmaceutical formulation. Int J Pharm Tech Res. 2011;3:248-52.

\section{Publisher's Note}

Springer Nature remains neutral with regard to jurisdictional claims in published maps and institutional affiliations.

Ready to submit your research? Choose BMC and benefit from:

- fast, convenient online submission

- thorough peer review by experienced researchers in your field

- rapid publication on acceptance

- support for research data, including large and complex data types

- gold Open Access which fosters wider collaboration and increased citations

- maximum visibility for your research: over $100 \mathrm{M}$ website views per year

At BMC, research is always in progress.

Learn more biomedcentral.com/submissions 